\title{
POETRY
}

JEAN MACKENZIE, 1014 - 7th Street East, Saskatoon, Saskatchewan. S7H OY8

\section{MARIGOLD HEAD}

Like a yellow flower burst into bloom on the slender stalk of a green cattail near the centre of the prairie slough

Marsh marigold head into black-petalled eyes belonging to a coal-black body startlingly decorated with white wing patches

Voice as violent as the arresting colours low hoarse croaking call song with low rasping notes ending in the long descending buzz of the Yellowheaded Blackbird.

\section{CLEVER JILL}

"Wheeoo! Wheeoo!"

Gray Jay

how did you get your nickname

of "Whisky Jack"?

Did you act

so friendly and tame

that one gray

boring day

someone invented a game

of making you frisky

by pouring you whisky?

And did your mate have enough brain to stay away

so that she would not receive the name of "Whisky Jill"?

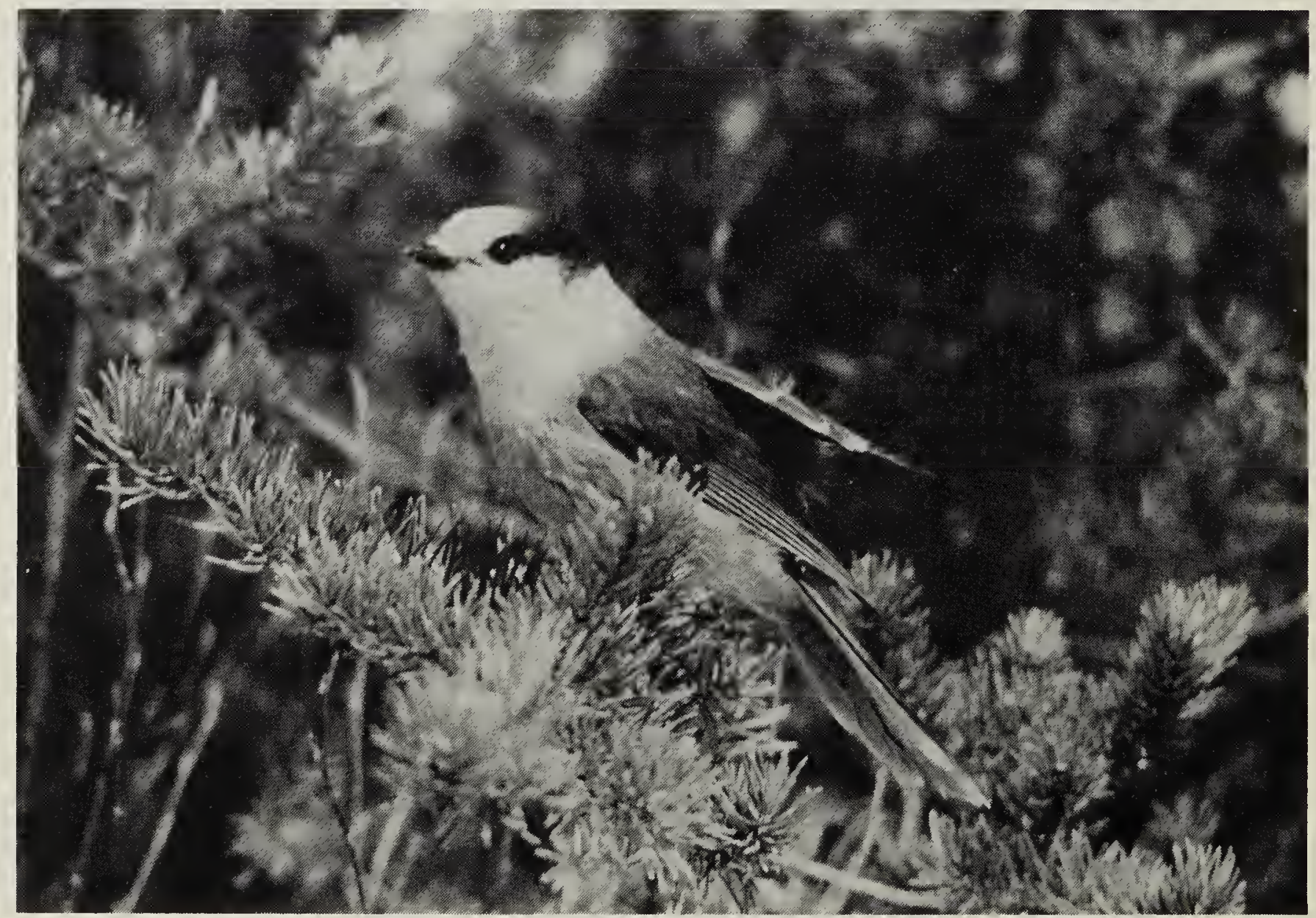

